\title{
Diet of a threatened pond frog differs over a small spatial scale
}

\author{
Deborah S. Bower*, Evan J. Pickett, James I. Garnham, Matthew L. Deboo, \\ Matthew R. McCurry, Rianne M. Mengerink, Michael J. Mahony, John Clulow
}

University of Newcastle, Callaghan, Newcastle, New South Wales 2308, Australia

\begin{abstract}
Suitability of habitat patches affects demographic processes and consequently influences the viability of populations. In order for managers to consider the potential of resources on a scale appropriate to their use, it is important to understand the processes that influence the ecology of threatened species. Differential growth rates of Litoria aurea (green and golden bell frog) at Sydney Olympic Park, Australia, may be explained by prey availability and diet. We tested: (1) whether food availability differed among precincts at Sydney Olympic Park and (2) whether the diet of $L$. aurea was influenced by availability of invertebrate prey. Diets were distinct among precincts and reflected the variation in biomass and richness of invertebrate assemblages. Precincts with greater biomass corresponded to areas with faster individual growth rates and greater habitat structure. The differences in diet and individual growth rates of $L$. aurea among precincts at Sydney Olympic Park demonstrate how caution must be applied to generalising population function, even within a small area.
\end{abstract}

KEY WORDS: Patchy habitat $\cdot$ Prey $\cdot$ Amphibian $\cdot$ Food $\cdot$ Litoria aurea

\section{INTRODUCTION}

Consideration of scale is crucial when managing threatened species because population function is affected by habitat patch suitability. While some patches may sustain healthy populations, other areas, with lower densities of individuals, are at an increased risk of extinction or are unviable (Hanski 1994). Therefore, for managers to accurately gauge the potential of resources on a scale appropriate to their use, it is important to understand the processes that influence the ecology of threatened species. For example, the distribution of mallee emu wrens at Murray-Sunset reserve, South Australia, is restricted to discrete habitat patches that have been unburnt for $15 \mathrm{yr}$ (Brown et al. 2009). In this situation, managers must allocate species-specific actions, such as disturbance reduction within the isolated occupied patches, while operating large-scale land management, such as wildfire control, over the entire 633000 ha parkland. This multifaceted approach is necessary for the persistence of many threatened species that occupy patches of habitat.

Urban areas often provide heterogeneous habitats in close proximity to each other because development and restoration occur at different temporal and spatial scales (Cadenasso et al. 2007). In many urban areas, managers regulate ecological practices and, therefore, it is important to determine the most beneficial management regimes for threatened species. Green and golden bell frogs Litoria aurea are a threatened species that persist primarily in isolated, urban areas on the south-east coast of Australia (Mahony 1996). They have disappeared throughout $90 \%$ of their former range in the last $40 \mathrm{yr}$, following rapid, widespread declines that are usually attributed to the amphibian chytrid fungus, Batrachochytrium dendrobatidis, and now persist in iso- 
lated populations in a wide variety of habitats (Mahony 1996). Despite their decline in Australia, L. aurea are invasive in New Zealand, Vanuatu and New Caledonia (Bishop 2008). The species' ability to persist in such a diversity of habitats suggests that it is a generalist with few specific requirements. One managed population occurs at Sydney Olympic Park (SOP), Sydney, New South Wales, Australia, a small (320 ha) region with heterogeneous habitat types. The area has been surveyed and managed since 1996 to directly ensure the population's persistence (Darcovich \& O'Meara 2008).

The population size of Litoria aurea at SOP is small, and is therefore inherently exposed to extinction processes. The population experiences high annual mortality (Pickett et al. in press), probably in part due to Batrachochytrium dendrobatidis (Penman et al. 2008, Stockwell et al. 2008, 2010). The compensatory high fecundity and growth rate of $L$. aurea allows the population to persist with high turnover and size variability (Hamer \& Mahony 2007, Pickett et al. in press). However, individual growth rates differ among 3 spatially distinct sites: individuals in Narawang Wetland and Kronos Hill grow faster than those in the Brickpit (Pickett et al. in press). Determining factors that influence growth may be important to demography. For example, fast-growing individuals may mature faster and contribute to reproduction earlier, which would in turn increase population growth and viability (Pickett et al. in press).

The difference in growth rates of Litoria aurea at SOP could be explained by a number of factors. One hypothesis is that frogs may have differential access to resources due to variability in prey items. We tested: (1) whether prey resource availability differed among precincts at SOP and (2) whether the diet of $L$. aurea was influenced by availability of invertebrate prey.

\section{MATERIALS AND METHODS}

\section{Study site}

SOP is a restored industrial wasteland in the western suburbs of Sydney, Australia. Litoria aurea was discovered in the grounds of the park prior to developing the site for the 2000 Sydney Olympic Games (Darcovich \& O'Meara 2008). A large restoration strategy was implemented to offset habitat loss and increase the distribution of $L$. aurea in an attempt to ensure the persistence of the population (Pickett et al. 2013). Currently, the park contains 150 ponds of varying size and hydrological regimes, providing a selection of habitat for aquatic fauna. Within the park, L. aurea was studied in 3 distinct precincts (335 $51^{\prime} \mathrm{S}, 151^{\circ} 04^{\prime} \mathrm{E}$; Fig. 1). The Brickpit precinct is a disused quarry where works finished in 1998; it is 24 ha in size and contains 45 ponds of varying size. Transects were established around the central and largest ponds. The Kronos Hill/Wentworth Common area, located north of the Brickpit, was completed between 1998 and 2000 (Darcovich \& O'Meara 2008), is 40 ha in size and contains 37 habitat ponds. However, owing to a skewed distribution of frogs at this site, our study focused on the western ponds of Kronos Hill. In 1999, additional habitat was created on remediated land north of Kronos Hill/Wentworth Common in the area now known as Narawang Wetland. Narawang Wetland consists of 20 ha containing 22 habitat ponds. Transects were set around the most easterly part of the wetlands (Fig. 1) and were selected to represent the area where $L$. aurea were most heavily sampled for stomach flushing. Longterm demographic studies have detected little movement between precincts (Pickett et al. in press).

\section{Surveys and invertebrate sampling}

Surveys for Litoria aurea were conducted in 14 ponds within the 3 precincts between 2 and 22 February 2012 at SOP. Sampling of each pond occurred between 20:00 and 04:00 h. Individual $L$. aurea were captured inside a single-use disposable plastic bag to prevent potential pathogen transmission. Individuals were only stomach flushed once. Individuals greater than $35 \mathrm{~mm}$ snout-vent length (SVL) were identified by a passive integrated transponder tag (Christy 1996, Christy et al. 2007), whereas juveniles were identified by skin biopsy taken from toe webbing for genetic purposes. Stomach flushing was completed within 30 min of capture (Solé et al. 2005), and frogs were then released at the site of their capture. Dietary items were stored in $80 \%$ ethanol, identified to order (Zborowski \& Storey 2010), dried and weighed to the nearest $0.0001 \mathrm{~g}$ using a Sartorious BP 210 S electronic microbalance. Unidentifiable prey items were rare and excluded from count data, which was quantified by the number of whole animals or, where the organism was in many pieces, e.g. arachnids, by the number of abdomens.

Invertebrate sampling in the environment was completed between 19 and 23 February 2012. Between 5 and 7 belt transects, $20 \mathrm{~m}$ by $1 \mathrm{~m}$, were posi- 


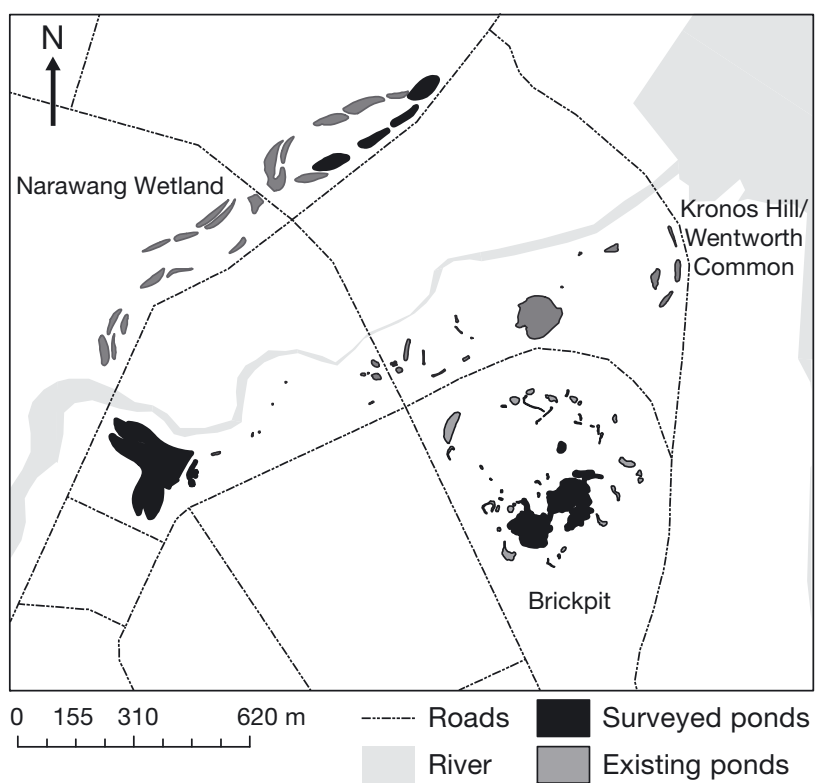

Fig. 1. Sydney Olympic Park, Sydney, NSW, Australia, showing the 3 precincts where invertebrate sampling and stomach flushing of Litoria aurea occurred in 2012

tioned perpendicular to the water's edge. The proportion of vegetation cover in each $2 \mathrm{~m}^{2}$ section of transect was summed and the total proportion of coverage was calculated. Vegetation was grouped into one of 5 main categories that reflected its structure: grass, reeds, bare ground, woodland or leaf litter. Invertebrate sampling was completed between 09:00 and 11:00 h over $5 \mathrm{~d}$. Each metre of transect was sampled by 2 min of aerial sweep netting (net $152 \mathrm{~mm}$ diameter, $0.9 \times 0.3 \mathrm{~m}$ mesh, $18 \mathrm{~cm}$ long, Australian Entomological Supplies Pty Ltd) and 2 min of active searching. Invertebrates were stored in $80 \%$ ethanol and identified to order (Zborowski \& Storey 2010). The cumulated sample from each transect was weighed to the nearest $0.0001 \mathrm{~g}$ using a Sartorious BP 210S electronic microbalance. Our research was conducted in accordance with institutional, national and international guidelines concerning the use of animals in research and the sampling of endangered species.

\section{Statistical analysis}

Primer 6 (version 6.1.15) was used to analyse all multi-dimensional scaling (MDS) and diversity indices. Euclidean distance was used to investigate the composition of prey taxa among sites by using the presence/absence of prey taxa detected in L. aurea stomachs in each pond; the precinct was used as a grouping variable. Bray-Curtis similarity was used to investigate the similarity of invertebrate composition in the sites by using the abundance of invertebrate taxa in each transect as the site, and the habitat precinct as a grouping factor. A one-way ANOVA was used to test for differences in diversity, transformed richness (natural log), evenness, abundance and biomass of invertebrates sampled in transects among precincts. The proportion of vegetation in each transect was transformed (arc sine) to meet assumptions of normality before a one-way ANOVA was employed to compare variance among precincts. Linear mixed-effects models (assuming a normal distribution) were used to explore variability in the mass of frog gut contents. Precinct was included as a fixed effect; individual frogs were included as random effects. Pond and SVL of frogs were included in the initial model, and then removed in the final model owing to non-significance. Univariate models were completed in SPSS version 9.

\section{RESULTS}

The proportion of vegetation cover in each transect differed among precincts $\left(F_{8,75}=5.97, \mathrm{p}<0.001\right.$; Fig. 2). The Brickpit habitat primarily comprised bare ground $(56 \%)$ and grass $(44 \%)$, with few trees. Narawang Wetland was dominated by grass $(44 \%)$, woodlands $(33 \%)$ and leaf litter $(23 \%)$. Kronos Hill was predominantly grassy ( $83 \%$ ) with small areas of woodland $(12 \%)$.

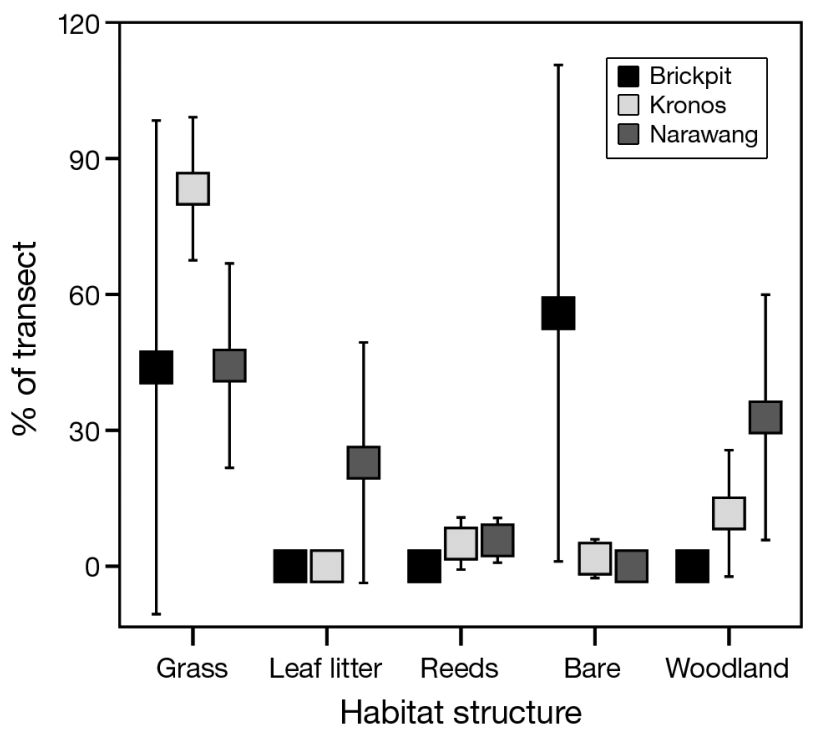

Fig. 2. Mean percentage of habitat type in 3 precincts at Sydney Olympic Park in 2012. Error bars are 95\% confidence intervals (CI) 


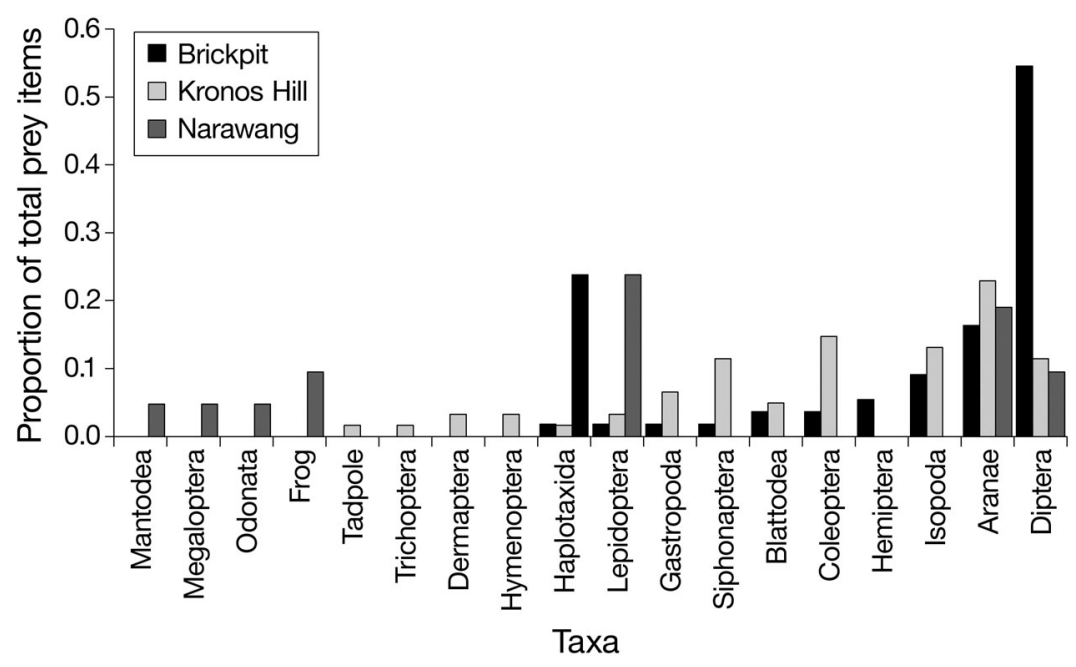

Fig. 3. Proportion of Litoria aurea gut contents sampled from each taxa at 3 precincts at Sydney Olympic Park in 2012. Frogs and tadpoles are presented separately to demonstrate the occurrence of aquatic foraging
Invertebrate surveys sampled 38 taxa. Mean biomass of dried invertebrates in transects at Narawang Wetland $(1.5 \pm 0.4 \mathrm{~g})$ was higher than in the Brickpit $(0.3 \pm 0.5 \mathrm{~g})$, while Kronos Hill was intermediate (1.0 $\left.\pm 0.3 g_{i} F_{2,15}=7.62, \mathrm{p}<0.005\right)$. Taxa richness was higher in transects in Narawang Wetland (17.6 \pm $0.78)$ and Kronos Hill $(17.3 \pm 1.9)$ than in the Brickpit $\left(13 \pm 0.6 ; F_{2,15}=7.02, \mathrm{p}<0.01\right)$. However, the mean abundance (605 $\left.\pm 67, F_{2,15}=1.244, \mathrm{p}=0.32\right)$, evenness $\left(0.62 \pm 0.62, F_{2,15}=0.60, \mathrm{p}=0.56\right)$ and diversity $\left(0.7 \pm 0.2, F_{2,15}=2.49, \mathrm{p}=0.12\right)$ of invertebrates in transects did not differ significantly among precincts.

Sixty Litoria aurea gut samples contained 137 individual prey items, with 1 to 16 items per gut. Sixteen invertebrate taxa were identified from gut contents, all of which were sampled during invertebrate surveys (Fig. 3). Gut contents included both aquatic and terrestrial invertebrates, but also tadpoles (unknown sp.) and 2 other frog species (Litoria fallax and Limnodynastes peronii). Stomach flushing of $13 \mathrm{~L}$. aurea did not return any prey items.

The similarity of prey contents from Litoria aurea guts differed according to precinct in an ordination (MDS) (Fig. 4). Diptera $(\mathrm{n}=33$ ) comprised $54 \%$ of food items in $L$. aurea in the Brickpit, but only represented a small proportion of the diet in Kronos Hill and Narawang Wetland. Individual prey items in guts of $L$. aurea from Narawang Wetland had significantly greater mean biomass than those from Kronos Hill and the Brickpit $\left(F_{2,23}=5.06, \mathrm{p}<0.02\right.$; Fig. 5). However, differences in prey biomass among precincts were not determined by frog size; there was no significant interaction between precinct and SVL $\left(F_{2,13}=0.34, \mathrm{p}=0.721\right)$.

\section{DISCUSSION}

Litoria aurea consumed a wide variety of prey types, but diet was distinct among precincts in close proximity to one another at SOP. L. aurea in the Brickpit ate lighter prey items than at Narawang Wetland, potentially because of differences in the availability of prey and taxa among sites. Invertebrate sampling demonstrated that a much lower biomass occurred in the Brickpit, where L. aurea diet had a larger representation of dipterans and fewer taxa overall. In Narawang Wetland, the invertebrate assemblage was higher in both biomass and richness relative to the other sites, providing the frogs with greater choice and biomass of food items. Kronos Hill was less distinct from the other sites and had invertebrate assemblages resembling both the Brickpit and Narawang Wetland.

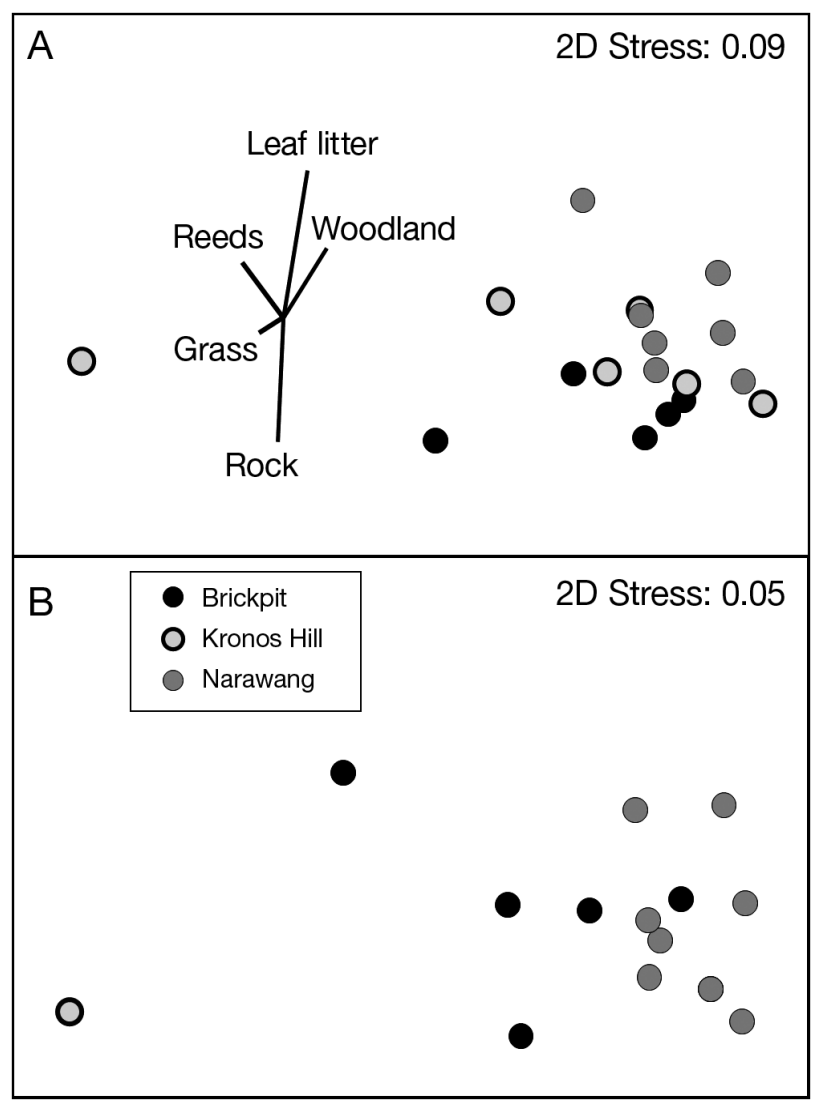

Fig. 4. Ordination of (A) invertebrates sampled on transects and (B) invertebrates sampled from gut contents of Litoria aurea at Sydney Olympic Park in 2012, grouped by habitat precinct 

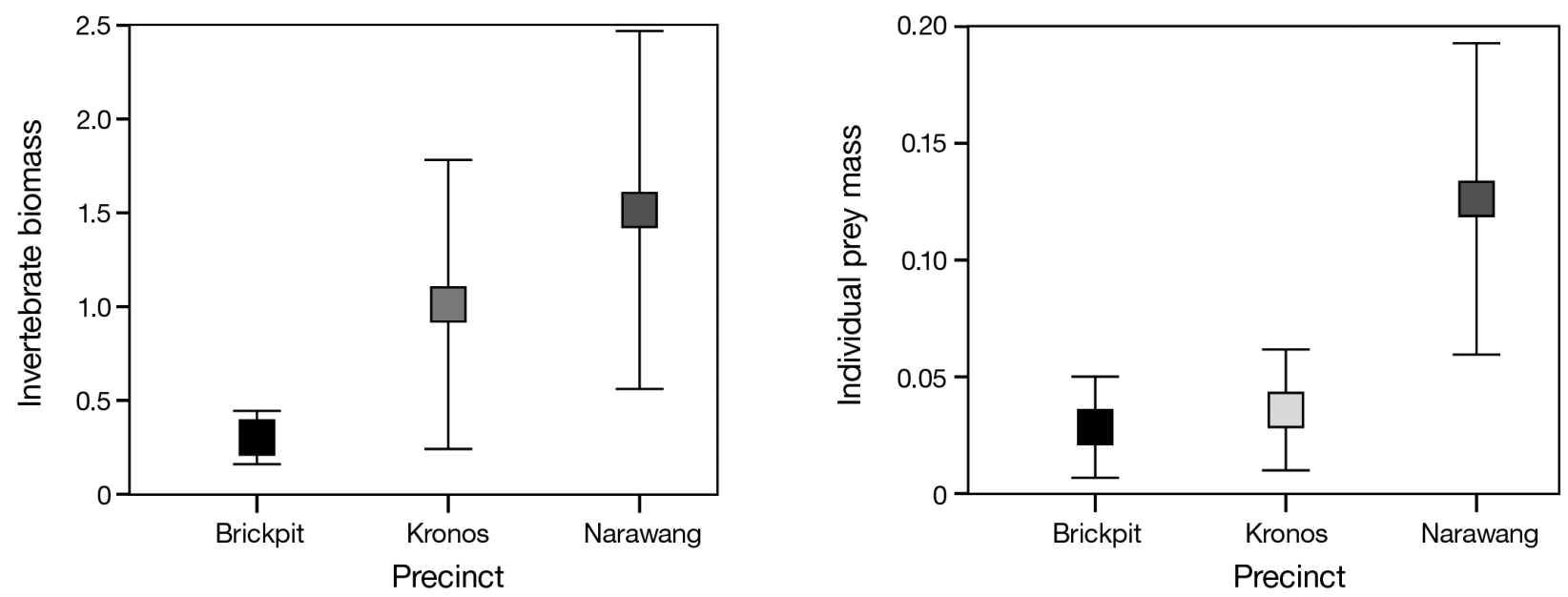

Fig. 5. (A) Mean biomass of invertebrates collected from transects in each precinct at Sydney Olympic Park in 2012. (B) Mean mass of prey items from Litoria aurea guts in each precinct Error bars are $95 \% \mathrm{CI}$

Differences in invertebrate assemblages among precincts may be explained by disparity in habitat structure at SOP. A higher proportion of grass and trees, and a strong ground layer of leaf litter, dominated Narawang Wetland, with no areas of bare ground. Invertebrate assemblages are responsive to small-scale changes in microhabitat (Kremen et al. 1993), suggesting that differences in habitat among precincts likely account for the greater biomass and richness of invertebrates in Narawang Wetland compared with the Brickpit. Narawang Wetland had habitat with multiple strata which provide a variety of fossorial and arboreal shelter sites, and consequently had the highest biomass and richness of invertebrates. In stark contrast, the lack of soil and large areas of bare ground and rock that accounted for over half the transect area at the Brickpit provided little habitat diversity or refuge for invertebrates. The mown grass at Kronos Hill lacked the woodland and leaf litter of Narawang Wetland, but had more structure than the bare rock in the Brickpit. The intermediate structure in Kronos Hill was reflected in the invertebrate assemblages, which resembled those in both of the other precincts.

Differences in prey availability among precincts reflect the differences in growth rates of frogs among precincts in SOP. Litoria aurea in Narawang Wetland and Kronos Hill reach a length indicative of maturity within a single season of growth, whereas females from the Brickpit take an extra $50 \mathrm{~d}$ on average (Pickett et al. in press). Differences in growth rate reflect the comparatively high biomass of invertebrates eaten by L. aurea in Narawang Wetland compared with the Brickpit. However, in Kronos Hill the growth rates and prey availability were greater than those in the Brickpit, while the mass of prey was more similar to that in the Brickpit, suggesting that the diet biomass may not have been reflected by the stomach flushing. This may be explained by differences in the decomposition rate of prey, which can confound dietary studies by over representing slow-digesting prey items (Hyslop 1980). In addition, while the difference in resource availability reflected variation in growth rates of $L$. aurea in the present study, other alternative factors need to be considered as potential contributors to differential growth rates, such as differences in microclimate, including temperature (Browne \& Edwards 2003), which affects growth rate of ectothermic animals.

Areas of highly productive habitat, with a high richness and abundance of invertebrate taxa supporting faster-growing Litoria aurea, may be crucial components for an optimal design of constructed $L$. aurea habitat. L. aurea is often the subject of translocations to newly constructed habitat relating to development applications, because populations often reside on industrial and urban land (White \& Pyke 2008). Designing habitat that will maximise the growth rate of $L$. aurea could be particularly beneficial, because susceptibility to Batrachochytrium dendrobatidis is implicated in failure of reintroductions (Stockwell et al. 2008). For species that suffer high mortality, the difference between reaching maturity in the first or second breeding season could alter the viability of the population. The differences in diet and demographic rates of $L$. aurea among precincts at SOP demonstrate how caution must be applied to generalising population function, even within a small area. Ecological studies aimed at measuring baseline resource requirements required to optimise demo- 
graphics of managed populations should take heterogeneity at the small to micro-landscape scales, as well as larger landscape scales, into account.

Acknowledgements. The University of Newcastle's 2012 Conservation Biology class assisted with data collection. Jenny O'Meara and Kerry Darcovich provided site access and constructive input into the research plan and commented on the manuscript. Graham Pyke demonstrated methods of stomach flushing and provided advice. Simon Linke and Kim Colyvas advised on statistics. This study was funded by ARC Linkage grant LP0989459 (industry partners: Australian Research Council, Sydney Olympic Park Authority, Strathfield Council, South Australian Museum, NSW Roads and Traffic Authority, NSW Office of Environment and Heritage). Approvals were issued by the University of Newcastle Animal Care and Ethics Committee (A2008-165) and NSW National Parks Scientific Licence (SL100190).

\section{LITERATURE CITED}

Bishop PJ (2008) Bell frog populations in New Zealandgood news or bad news? Aust Zool 34:408-413

Brown S, Clarke M, Clarke R (2009) Fire is a key element in the landscape-scale habitat requirements and global population status of a threatened bird: the mallee emuwren (Stipiturus mallee). Biol Conserv 142:432-445

Browne R, Edwards D (2003) The effect of temperature on the growth and development of the endangered green and golden bell frog (Litoria aurea). J Therm Biol 28: 295-299

> Cadenasso ML, Pickett ST, Schwarz K (2007) Spatial heterogeneity in urban ecosystems: reconceptualizing land cover and a framework for classification. Front Ecol Environ 5:80-88

Christy M (1996) The efficacy of using passive integrated transponder (PIT) tags without anaesthetic in free-living frogs. Aust Zool 30:139-142

Christy MT, Savidge JA, Rodda GH (2007) Multiple pathways for invasion of anurans on a Pacific island. Divers Distrib 13:598-607

Darcovich K, O'Meara J (2008) An olympic legacy: green and golden bell frog conservation at Sydney Olympic Park 1993-2006. Aust Zool 34:236-248

Hamer A, Mahony M (2007) Life history of an endangered

Editorial responsibility: Brendan Godley,

University of Exeter, Cornwall Campus, UK amphibian challenges the declining species paradigm. Aust J Zool 55:79-88

Hanski I (1994) Patch-occupancy dynamics in fragmented landscapes. Trends Ecol Evol 9:131-135

- Hyslop E (1980) Stomach contents analysis - a review of methods and their application. J Fish Biol 17:411-429

Kremen C, Colwell RK, Erwin TL, Murphy DD, Noss RF, Sanjayan MA (1993) Terrestrial arthropod assemblages: their use in conservation planning. Conserv Biol 7 : 796-808

Mahony M (1996) The decline of the green and golden bell frog Litoria aurea viewed in the context of declines and disappearances of other Australian frogs. Aust Zool 30: 237-247

- Penman TD, Muir G, Magarey E, Burns E (2008) Impact of a chytrid-related mortality event on a population of the green and golden bell frog Litoria aurea. Aust Zool 34: 314-318

Pickett EJ, Stockwell MP, Bower DS, Garnham JI, Pollard CJ, Clulow J, Mahony MJ (2013) Achieving no net loss in habitat offset of a threatened frog required high offset ratio and intensive monitoring. Biol Conserv 157: $156-162$

Pickett EJ, Stockwell MP, Bower DS, Pollard CJ, Garnham JI, Clulow J, Mahony MJ (in press) Long-term demographic study reveals threat of stochastic extinction for remnant populations of a threatened amphibian. Aust Ecol

Solé M, Beckmann O, Pelz B, Kwet A, Engels W (2005) Stomach-flushing for diet analysis in anurans: an improved protocol evaluated in a case study in Araucaria forests, southern Brazil. Stud Neotrop Fauna Environ 40: $23-28$

Stockwell M, Clulow S, Clulow J, Mahony M (2008) The impact of the amphibian chytrid fungus Batrachochytrium dendrobatidis on a green and golden bell frog Litoria aurea reintroduction program at the Hunter Wetlands Centre Australia in the Hunter Region of NSW. Aust Zool 34:379-386

Stockwell M, Clulow J, Mahony M (2010) Host species determines whether infection load increases beyond disease causing thresholds following exposure to the amphibian chytrid fungus. Anim Conserv 13:62-71

White AW, Pyke GH (2008) Frogs on the hop: translocations of green and golden bell frogs Litoria aurea in Greater Sydney. Aust Zool 34:249-260

Zborowski P, Storey R (2010) Field guide to insects in Australia. New Holland, Chatswood

Submitted: July 15, 2013; Accepted: October 21, 2013

Proofs received from author(s): January 15, 2014 